\title{
Drug-eluting stents or coronary artery bypass grafting for unprotected left main coronary artery disease: a meta-analysis of four randomized trials and seventeen observational studies
}

Qing $\mathrm{Li}^{1}$, Zhi Zhang ${ }^{2}$ and Rui-Xing Yin ${ }^{1 *}$

\begin{abstract}
Background: The clinical application of drug-eluting stents (DES) or coronary artery bypass grafting (CABG) for unprotected left main coronary artery disease (ULMCAD) is still controversial. The purpose of this meta-analysis was to compare the safety and efficacy between DES and CABG for ULMCAD.

Methods: Databases of MEDLINE, EMBASE and the Cochrane Library were systematically searched.

Results: Twenty-one studies with 8,413 patients were included in this meta-analysis. The risk was lower in DES than in CABG groups at the early outcomes of death (risk ratio (RR): $0.49,95 \%$ confidence interval (Cl): 0.30-0.78), cerebrovascular events (RR: $0.19,95 \%$ Cl: $0.08-0.45$ ) and composite endpoint (RR: 0.53, 95\% Cl: 0.40-0.70); death after 2 years (RR: $0.81,95 \%$ Cl: $0.66-0.99$ ), 4 years (RR: $0.69,95 \%$ Cl: $0.53-0.90), 5$ years (OR: $0.76,95 \%$ Cl: $0.61-0.95$ ) and their total effect (RR: 0.79, 95\% Cl: 0.71-0.87); composite endpoint 1 year (RR: 0.69, 95\% Cl: 0.58-0.83), 4 years (RR: $0.69,95 \%$ Cl: $0.53-0.88), 5$ years (RR: $0.74,95 \%$ Cl: $0.59-0.92)$ and their total effect (RR: $0.78,95 \%$ Cl: $0.71-0.85$ ). There were no significant differences in the risk for the early outcomes of myocardial infarction (RR: $0.97,95 \% \mathrm{Cl}$ : 0.68-1.38), death 1 year (OR: 0.81, 95\% Cl: 0.57-1.15) and 3 years (OR: 0.85, 95\% Cl: 0.69-1.04), composite endpoint of 2 years (RR: $0.88,95 \% \mathrm{Cl}: 0.72-1.09$ ) and 3 years (RR: $0.87,95 \% \mathrm{Cl}: 0.73-1.04)$. Nonetheless, there was a lower risk for revascularization associated with CABG from 1 to 5 years and their total effect (RR: 3.77, 95\% Cl: 3.35-4.26). There was no difference in death, myocardial infarction, cerebrovascular events or revascularization at 1 year between RCT and observational groups.
\end{abstract}

Conclusions: Our meta-analysis indicates that DES has higher safety but higher revascularization than CABG in patients with ULMCAD in the 5 years after intervention.

Keywords: Drug-eluting stents, Coronary artery bypass grafting, Unprotected left main coronary artery disease, Safety and efficacy, Meta-analysis

\section{Background}

As is well known, approximately 4 to $9 \%$ of patients undergoing diagnostic coronary angiography [1] are found to have unprotected left main stenosis which has been shown to portend high mortality [2,3]. Percutaneous coronary intervention (PCI) involving drug-eluting stents

\footnotetext{
* Correspondence: yinruixing@163.com

'Department of Cardiology, Institute of Cardiovascular Diseases, the First Affiliated Hospital, Guangxi Medical University, 22 Shuangyong Road,

Nanning 530021 Guangxi, People's Republic of China

Full list of author information is available at the end of the article
}

(DES) have increasingly been used to treat unprotected left main coronary artery disease (ULMCAD) in recent years, although coronary artery bypass grafting (CABG) has been the treatment of choice historically $[4,5]$. One of the main limitations of PCI for ULMCAD is in-stent restenosis and the need for repeat revascularization, especially in bare-metal stents [6,7]; therefore, the European Society of Cardiology guidelines and American Heart Association guidelines suggest that PCI for ULMCAD should be only reserved for those who are poor candidates for CABG [8]. However, several meta-analyses [9-12] of

\section{Ciomed Central}

(c) 2013 Li et al.; licensee BioMed Central Ltd. This is an Open Access article distributed under the terms of the Creative Commons Attribution License (http://creativecommons.org/licenses/by/2.0), which permits unrestricted use, distribution, and reproduction in any medium, provided the original work is properly cited. 
DES versus CABG for ULMCAD showed that the results are controversial, and many new clinical trials have been published in recent years [13-16]. Therefore, it is necessary to conduct a new meta-analysis and to assess the safety and efficacy of DES and CABG among patients with ULMCAD in the early outcomes ( $\leq 30$ days or in-hospital) and 1 to 5 years follow-up, and it is also necessary to compare the difference in safety and efficacy of DES and CABG between RCT and observational groups.

\section{Methods}

\section{Search strategy}

The data of this meta-analysis were obtained from the following sources: MEDLINE via PubMed (from 1950 to June 2012), EMBASE (June 1980 to June 2012) and the Cochrane Library database (Cochrane Central Register of Controlled Trials, from 1991 to June 2012). The following keywords were used: "coronary artery bypass", "drug-eluting stent", "paclitaxel-eluting stent", "sirolimus-eluting stent", and "left main coronary artery". The above search strategy described was used to obtain titles and abstracts of studies that may have been relevant to this review. The titles and abstracts were screened independently by two authors (Q Li and Z Zhang), who discarded studies that were not applicable. When multiple reports from the same patients were found, only the study with the most complete data set was included in the meta-analysis. However, duplicate patients of different articles that have different types of data of outcomes were included both. Any disagreements were arbitrated by discussion with a third reviewer (RX Yin).

\section{Included and excluded studies}

Studies were included in this meta-analysis if they met the following criteria: 1) clinical trials published in peer-reviewed journals with full available text in English; 2) clinical trials comparing CABG with DES for LMCAD; 3) reporting at least one relevant clinical endpoint including revascularization, myocardial infarction, cerebrovascular events, death or the composite endpoint (death, myocardial infarction, or cerebrovascular events); and 4) follow-up duration $\geq 30$ days. Excluded studies: 1) studies using only bare-metal stents or mixtures of bare-metal stents and DES but not comparing DES with CABG separately in the PCI group were excluded from this study; 2) studies in which it was not possible to extract data from the published results as well as those studies that did not report appropriate outcomes were also excluded.

\section{Types of outcome measures}

The safety endpoints of this meta-analysis were death, cerebrovascular events, myocardial infarction and the composite endpoint of death, myocardial infarction or cerebrovascular events. The efficacy endpoint was revascularization. Death was defined as death from any cause. Myocardial infarction included Q-wave and non-Q-wave myocardial infarction. Cerebrovascular events included ischemic attacks, stroke and reversible ischemic neurological deficits. Revascularization was the need for repeated CABG or PCI.

\section{Data extraction and management}

Two investigators independently extracted data according to the author details and the following information was extracted from each study: methodological quality, first author, the year of publication, number of patients in each group (CABG or DES), baseline characteristics, interventions, outcomes, and duration of follow-up. Otherwise, probabilities of death or other endpoints were estimated from published Kaplan-Meier survival curves. Discrepancies were resolved by discussion. When repeated publications of the same trial were identified, data were extracted from the repeated publications and reported as a single trial.

\section{Quality of the evidence recommendations methodology}

The evidence recommendations in our meta-analysis were graded according to the Grading of Recommendations Assessment Development and Evaluation (GRADE) system by Grade software [17]. The quality of the evidence was classified in four levels: high $(\oplus \oplus \oplus \oplus)$, moderate $(\oplus \oplus \oplus \Theta)$, low $(\oplus \oplus \ominus \ominus)$ or very low $(\oplus \Theta \ominus \ominus)$.

\section{Statistical analysis}

We carried out statistical analysis by the Review Manager software 5.1.0 (updated in March 2011 by the Cochrane Collaboration). Dichotomous outcomes of individual studies were expressed as risk ratio (RR) with 95\% confidence intervals (CI). The pooled effects were calculated using fixed-effects models when there was no significant heterogeneity but the random effects model was analyzed to ensure robustness of the model chosen and susceptibility to outliers, or using random effects models when there was significant heterogeneity. The fixed effects model was analyzed to ensure robustness of the model chosen and susceptibility to outliers. The point estimate of the RR was considered statistically significant at the 2 -tailed $P \leq 0.05$ level. Heterogeneity was analyzed using a $\chi^{2}$ test on $\mathrm{N}-1$ degrees of freedom [18]. $I^{2}$ values of $25 \%, 50 \%$ and $75 \%$ correspond to low, medium and high levels of heterogeneity, respectively. Subgroup analysis was used to explore possible sources of heterogeneity (e.g., duration of follow-up, type of outcomes and study quality). Sensitivity analyses were performed omitting a single study at a time or analyzing another model chosen. If enough studies were identified, funnel plots were used to investigate reporting biases [19]. The baseline characteristics were analyzed with $\chi^{2}$ test for categorical variables. 


\section{Results}

Characteristics of included studies

Twenty-one studies met our criteria for inclusion in the meta-analysis (Figure 1). Four studies were randomized controlled trials $[13,15,20,21]$ and seventeen studies were observational studies [4-8,14,16,22-36]. Several studies may have had duplicate patients but they had different types data of outcomes, e.g., one study [20] included death outcomes but another [13] did not. A total of 8,413 patients were included in the analysis. There were 4,731 patients who received CABG and 3,682 patients who received PCI with DES. The main characteristics of the studies are shown in Table 1.

\section{Baseline characteristics of the trials}

The baseline clinical characteristics between the PCI and CABG groups are detailed in Table 2. There were no significant differences in the prevalence of hypertension, current smoking, diabetes mellitus, previous stroke, and chronic renal failure between the two groups $(P>0.05$ for all). The proportions of females and previous PCI were lower but the prevalence of hyperlipidemia, previous myocardial infarction and right coronary artery disease were higher in CABG than in PCI groups $(P<0.05$ for all).

\section{Clinical outcomes}

\section{The early outcomes ( $\leq 30$ days or in-hospital)}

The early outcomes of DES and CABG groups and the pooled effects are shown in Figure 2. Pooled effects indicated that CABG group had higher risk of death (RR: 0.49, 95\% CI: 0.30-0.78, $P=0.003)$, cerebrovascular events (RR: $0.19,95 \% \mathrm{CI}: 0.08-0.45, P=0.0002$ ) and composite endpoint (RR: $0.53,95 \% \mathrm{CI}: 0.40-0.70, P<0.00001$ ) than the PCI group. There was no difference in myocardial infarction (RR: 0.97, 95\% CI: 0.68-1.38, $P=0.86$ ) between CABG and PCI groups.

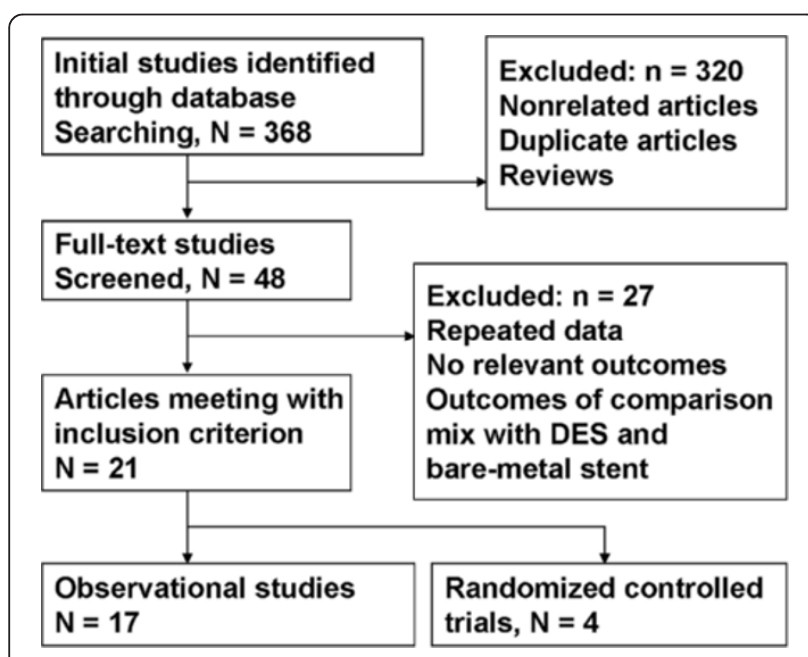

Figure 1 Flow chart showing study selection process.

\section{Death after 1 to 5 years post-operation}

Death after 1 to 5 years post-operation between the $\mathrm{CABG}$ and PCI groups is shown in Figure 3. Pooled effects showed that CABG group had higher risk of death than the PCI group after 2 years (RR: 0.81, 95\% CI: $0.66-0.99, P=0.04$ ), 4 years (RR: $0.69,95 \% \mathrm{CI}: 0.53-0.90$, $P=0.007$ ), 5 years (OR: $0.76,95 \% \mathrm{CI}: 0.61-0.95, P=0.02$ ) and total pooled outcome (RR: $0.79,95 \% \mathrm{CI}: 0.71-0.87$, $P<0.00001)$. There was no difference in deaths at 1 year (RR: $0.80,95 \%$ CI: $0.63-1.02, P=0.07$ ) and 3 years (OR: 0.85, 95\% CI: $0.69-1.04, P=0.11)$ between the CABG and PCI groups.

\section{Composite endpoint at 1 to 5 years post-operation}

The outcomes of composite endpoint of death, myocardial infarction and cerebrovascular events at 1 to 5 year postoperation between CABG and PCI groups are detailed in Figure 4. Pooled effects showed that CABG group had higher composite endpoint risk than PCI group after 1 year (RR: $0.69,95 \% \mathrm{CI}: 0.58-0.83, P=0.0001$ ), 4 years (RR: $0.69,95 \%$ CI: $0.53-0.88, P=0.003), 5$ years (RR: 0.74 , 95\% CI: $0.59-0.92, P=0.007)$ and total pooled outcome (RR: $0.78,95 \%$ CI: $0.71-0.85, P<0.00001)$. There was no difference in composite endpoint at 2 years (RR: $0.88,95 \%$ CI: $0.72-1.09, P=0.24$ ) and 3 years (RR: $0.87,95 \% \mathrm{CI}$ : $0.73-1.04, P=0.14$ ) between the CABG and PCI groups.

\section{Revascularization at 1 to 5 years post-operation}

The outcomes of revascularization at 1 to 5 years postoperation between PCI and CABG groups are shown in Figure 5. Pooled effects showed that PCI group had higher revascularization risk than CABG group at 1 year (RR:3.38, 95\% CI: 2.75-4.15, $P<0.00001), 2$ years (RR: 3.81, 95\% CI: $2.93-4.95, P<0.00001$ ), 3 years (RR: 4.42 , 95\% CI: 3.40-5.75, $P<0.00001)$, 4 years (RR: $3.22,95 \%$ CI: $2.28-4.54, P<0.00001$ ) and 5 years (RR: $4.43,95 \%$ CI: 3.08-6.37, $P<0.00001)$, and total pooled outcome (RR: $3.77,95 \%$ CI: $3.35-4.26, P<0.00001)$.

Outcomes at 1 year between RCT and observational groups The outcomes of RCT and observational groups at 1 year are shown in Figures 6, 7, 8, 9. Pooled effects showed that there were no different outcomes between RCT and observational groups in death, myocardial infarction, cerebrovascular events or revascularization. There were also no differences in both death and myocardial infarction for CABG and PCI in both RCT and observational groups $(P>0.05$ for each). The PCI group had higher revascularization risk than the CABG group $(P<0.00001)$, whereas the CABG group had higher cerebrovascular events risk than the PCI group $(P=0.001)$ in the two groups. 
Table 1 Main characteristics of included studies

\begin{tabular}{|c|c|c|c|c|c|c|c|}
\hline Study & Year & $\begin{array}{l}\text { Patients } \\
\text { (DES/CABG) }\end{array}$ & Study year & Study design & $\begin{array}{l}\text { Age (years) } \\
\text { (DES/CABG) }\end{array}$ & Outcome & $\begin{array}{l}\text { Follow-up } \\
\text { period }\end{array}$ \\
\hline Lee et al. [27] & 2006 & $50 / 123$ & $2003-2006$ & Observational & $70 / 72$ & death, MI, TVR, stroke & 1 \\
\hline Chieffo et al. [24] & 2006 & $107 / 142$ & 2002-2004 & Observational & $68 / 64$ & death, MI, TVR, stroke, MACCE & 1 \\
\hline Palmerini et al. [29] & 2007 & $98 / 161$ & $2003-2006$ & Observational & $78 / 81$ & death, MI, TVR & 2 \\
\hline Sanmartin et al. [32] & 2007 & $96 / 245$ & $2000-2005$ & Observational & $66 / 66$ & death, MI, TVR, stroke, MACCE & 1 \\
\hline Makikallio et al. [28] & 2008 & $49 / 238$ & $2005-2007$ & Observational & $72 / 70$ & death, MI, TVR, stroke, MACCE & 1 \\
\hline White et al. [35] & 2008 & $67 / 67$ & 2003-2007 & Observational & $72 / 68$ & death, MACCE & 2 \\
\hline Seung et al. [33] & 2008 & $396 / 396$ & $2003-2006$ & Observational & $66 / 66$ & death, TVR, MACCE & 3 \\
\hline Boudriot et al. [20] & 2008 & $79 / 80$ & $2003-2007$ & $\mathrm{RCT}$ & $69 / 66$ & death, MI, TVR, MACCE & 1 \\
\hline Cheng et al. [22] & 2009 & $94 / 216$ & $2000-2007$ & Observational & $67 / 68$ & death, TVR, MACCE & 3 \\
\hline Ghenim et al. [25] & 2009 & $105 / 106$ & 2004-2007 & Observational & $80 / 79$ & TVR, MACCE & 1 \\
\hline Morice et al. [21] & 2010 & $357 / 348$ & 2005-2007 & $\mathrm{RCT}$ & $66 / 65$ & death, MI, TVR, stroke & 1 \\
\hline Chieffo et al. [23] & 2010 & $107 / 142$ & 2002-2004 & Observational & $63 / 67$ & death, MI, TVR, stroke, MACCE & 5 \\
\hline Kang et al. [26] & 2010 & $205 / 257$ & $2003-2006$ & Observational & $64 / 65$ & death, MI, TVR, stroke, MACCE & 3 \\
\hline Park et al. [31] & 2010 & $784 / 690$ & 2003-2006 & Observational & $63 / 64$ & death, TVR, MACCE & 5 \\
\hline Park et al. [30] & 2010 & $176 / 219$ & 2003-2004 & Observational & $61 / 62$ & death, TVR, MI, stroke & 5 \\
\hline Shimizu et al. [34] & 2010 & $64 / 89$ & 2004-2007 & Observational & $71 / 70$ & MI, TVR, stroke & 1 \\
\hline Wu et al. [36] & 2010 & $131 / 245$ & $2003-2006$ & Observational & $62 / 64$ & death, TVR, MACCE & 4 \\
\hline Boudriot et al. [13] & 2011 & $100 / 101$ & 2003-2009 & $\mathrm{RCT}$ & $66 / 69$ & death, MI, TVR, MACCE & 1 \\
\hline Park et al. [15] & 2011 & $300 / 300$ & 2004-2009 & $\mathrm{RCT}$ & $61 / 62$ & death, MI, TVR, stroke & 2 \\
\hline Caggegi et al. [14] & 2011 & $222 / 361$ & $2002-2010$ & Observational & $67 / 66$ & death, MI, TVR & 1 \\
\hline Rittger et al. [16] & 2011 & $95 / 205$ & 2004-2007 & Observational & $71 / 68$ & death, stroke, TVR & 2 \\
\hline
\end{tabular}

MACCE: Major adverse cardiac cerebrovascular events; MI: Myocardial infarction; TVR: Target vessel revascularization.

Sensitivity analysis

Sensitivity analyses were performed to assess the contribution of each study to the pooled estimate and by excluding individual studies one at a time and recalculating the pooled RR estimates for the remaining studies. Eliminating the studies with more than 300 patients or fewer than
100 patients in each group did not substantially change the pooled point estimate. Moreover, analysis of four RCTs separately did not also substantively alter the overall result of our analysis. Last but not least, performing transition of model also did not substantially change the pooled point estimate.

Table 2 Baseline clinical characteristics

\begin{tabular}{llll}
\hline Characteristic & PCI & CABG & $P\left(x^{2}\right)$ \\
\hline Number & 3682 & 4731 & $862 / 3725$ \\
Female/Sample size & $756 / 2644$ & $2529 / 4008$ & $<0.001$ \\
Hypertension/Sample size & $1759 / 2858$ & $1306 / 3804$ & 0.190 \\
Current smoking/Sample size & $893 / 2763$ & $1903 / 3771$ & 0.088 \\
Hyperlipidemia/Sample size & $1341 / 2809$ & $1374 / 4009$ & 0.029 \\
Diabetes mellitus/Sample size & $959 / 2858$ & $522 / 3401$ & 0.536 \\
Previous myocardial infarction/Sample size & $320 / 2537$ & $254 / 2376$ & 0.003 \\
Previous stroke/Sample size & $204 / 1882$ & $379 / 2809$ & 0.876 \\
Previous PCI/Sample size & $415 / 2022$ & $237 / 3465$ & $<0.001$ \\
CRF/Sample size & $156 / 2614$ & $1699 / 2509$ & 0.171 \\
RCA/Sample size & $1009 / 1941$ & $<0.001$ \\
\hline
\end{tabular}




\section{Discussion}

The results of the present meta-analysis showed that the early subtotal outcomes of death, cerebrovascular events and composite endpoint; death at 2, 4 and 5 years postoperation and composite endpoint at 1, 4 and 5 years post-operation, combined with their total outcomes, were lower risk in PCI than in CABG groups. There was no difference in the risk for the early outcomes of myocardial infarction, death at 3 years and composite endpoint at 2 and 3 years. Nevertheless, there was a lower risk for revascularization associated with CABG. There was no significant difference in death, myocardial infarction, cerebrovascular events or revascularization between RCT and observational groups. 
Recently, three meta-analyses [10,12,37], including RCTs and observational studies, showed no significant differences in the safety between CABG and DES, and superiority of CABG to DES for repeated revascularization in patients with ULMCAD. A meta-analysis including 3,773 patients and follow-up of 3 years believed that PCI was emerging as an acceptable option. However, the PCI group in the meta-analysis was mixed with bare-metal stents and DES but did not compare DES with CABG separately, which might have led to the less robust results [37]. The meta-analysis by Lee et al. [10] included 8 clinical studies and 1 year follow-up. However, the number of patients in the CABG and DES groups was wrong in one study [38] and the total number of studies and patients was small, which may also have led to weak results. The meta-analysis by Zheng et al. [12] published in 2011 was heavily based on observational studies (13 observational studies and 2 RCTs) and a 5-year follow-up in the two groups, however, 
it abstracted and combined unadjusted risk estimates not only from randomized trials but also from observational studies, which did not strengthen the conclusion.

Two recent meta-analyses including a single RCT have been published. In one meta-analysis including three RCTs, Kajimoto et al. [9] showed that there was no significant difference in the risk of death and myocardial infarction in two groups but was superior to target vessel revascularization and major adverse cardiac and cerebrovascular events in CABG than in PCI group at 1 year. Therefore, they believed that $\mathrm{CABG}$ remains the standard of care for the treatment of left main coronary artery disease. 
However, the meta-analysis included a large power article [39] with 1,800 patients mixed with left main coronary artery disease and three-vessel coronary disease but not comparing the results of left main coronary artery disease in the two groups separately, which also affected the results.

The meta-analysis by Desch et al. [40] including four RCTs showed that there were no significant differences in the clinical endpoints of death and myocardial infarction between the PCI and CABG groups. While stroke was more frequent in surgical patients, the risk of repeated revascularization was higher in the PCI up to 2 years. Therefore they believe PCI to be useful only as an alternative to CABG in anatomically suited patients and with an increased risk of adverse surgical outcomes. However, the meta-analysis included an article [41] assessing mixed baremetal stents and DES but not comparing DES with CABG separately, and the size of the study population was small. 


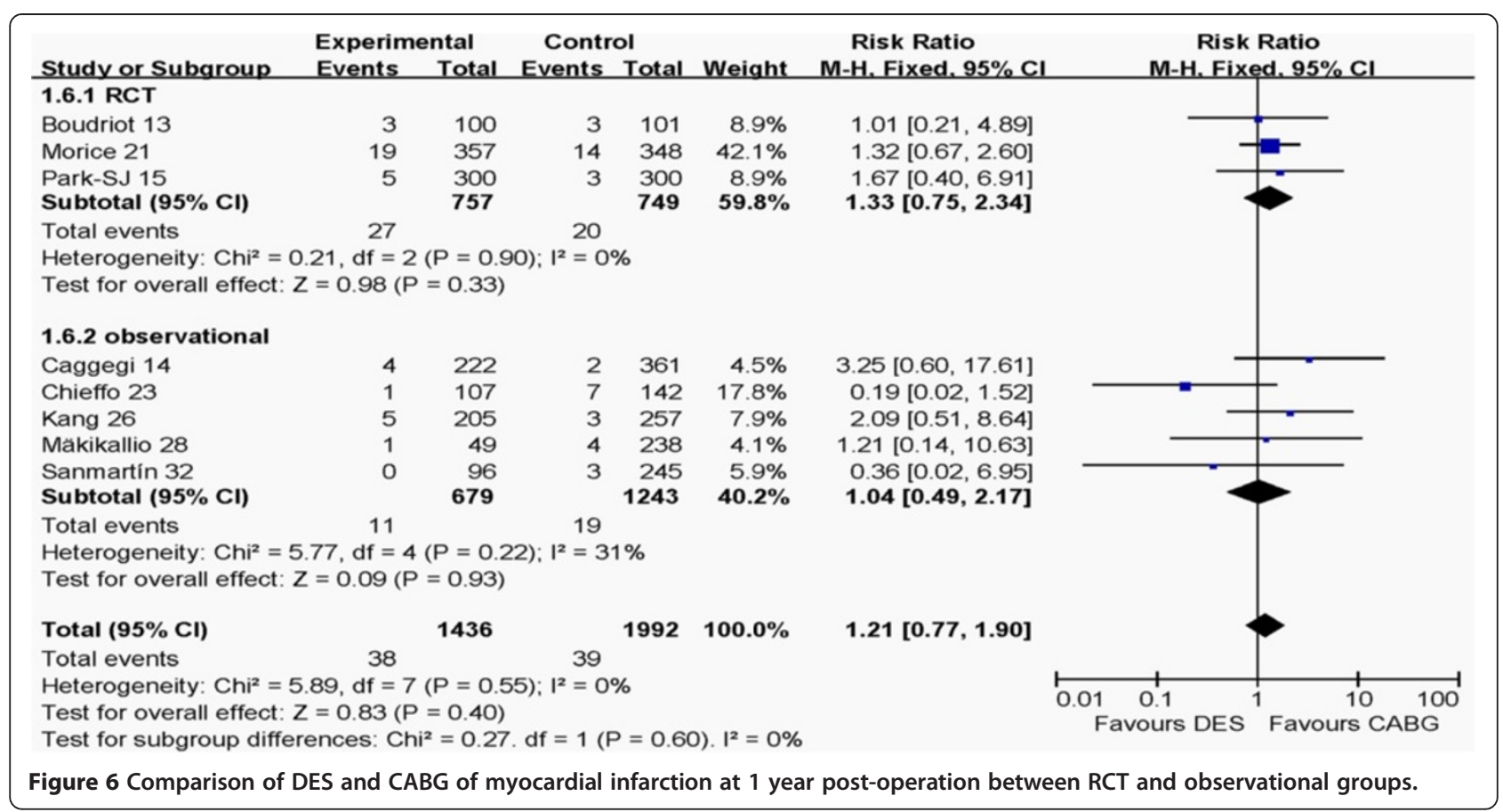

In the present study, however, we exclude the articles that mixed left main coronary artery disease and three-vessel coronary disease but did not compare left main coronary artery disease in the two groups separately, or articles assessing mixed bare-metal stents and DES but not comparing DES with CABG separately, and we included more studies (four RCTs and 17 observational studies) and larger number of patients (total 8,413). Further, we performed the systematic review using a different method, which may be the reason for the different outcomes with the previous meta-analyses. We also performed the analysis of RCT and observational groups separately, there was no significant difference in death, myocardial infarction, cerebrovascular events or revascularization between RCT and observational groups. These also made our conclusion more robust.

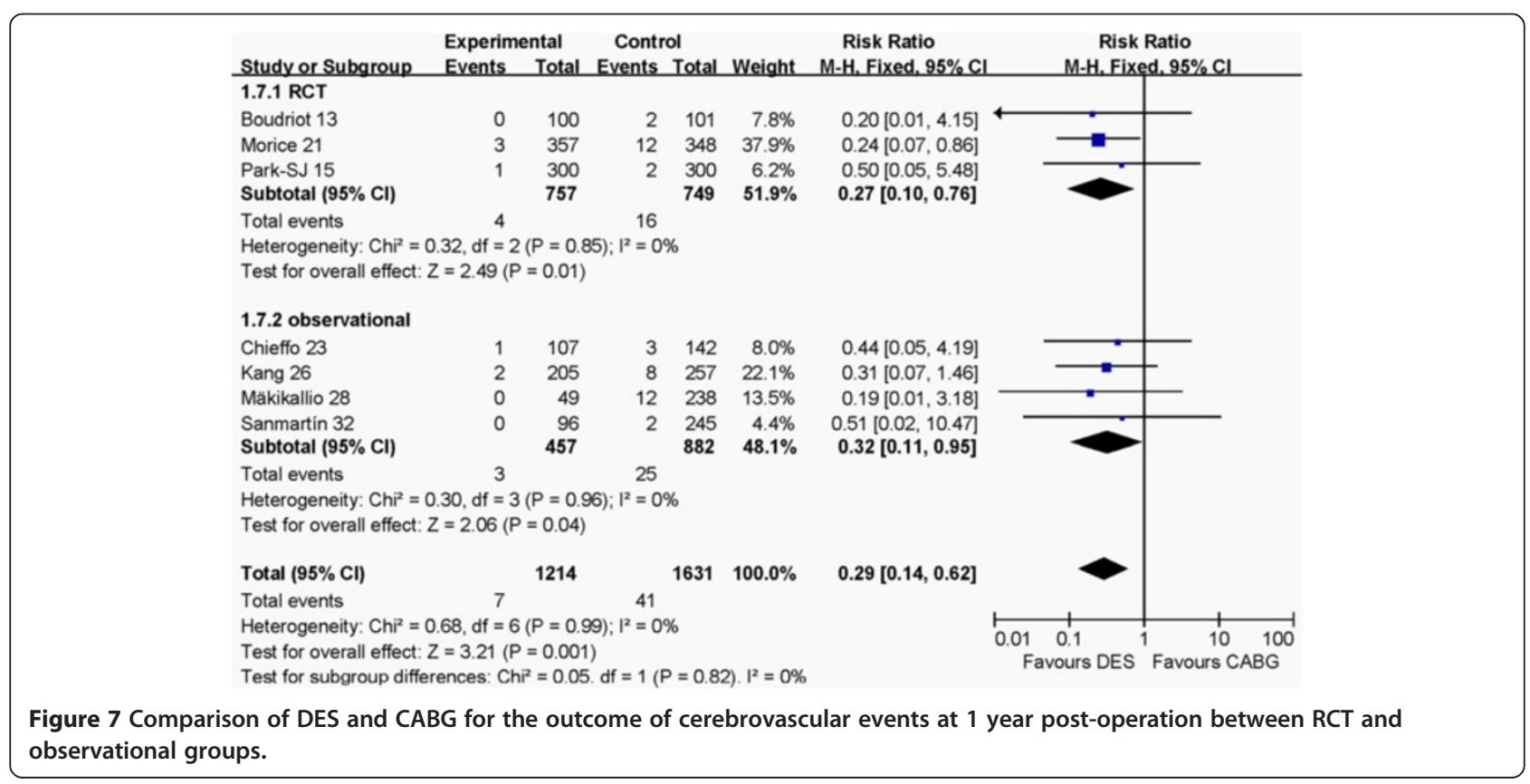




\section{Quality of the evidence}

Some of the evidence GRADE level was low because most of the included studies were poor quality. Seventeen studies were observational studies and were not performed with the method of randomization and allocation concealment, which might lead to selection bias and an exaggerated RR. Combined with not performing methods of blinding could result in performance, attrition and detection bias. These method limitations caused down grade of the quality of evidence. On the other hand, some differences in baseline

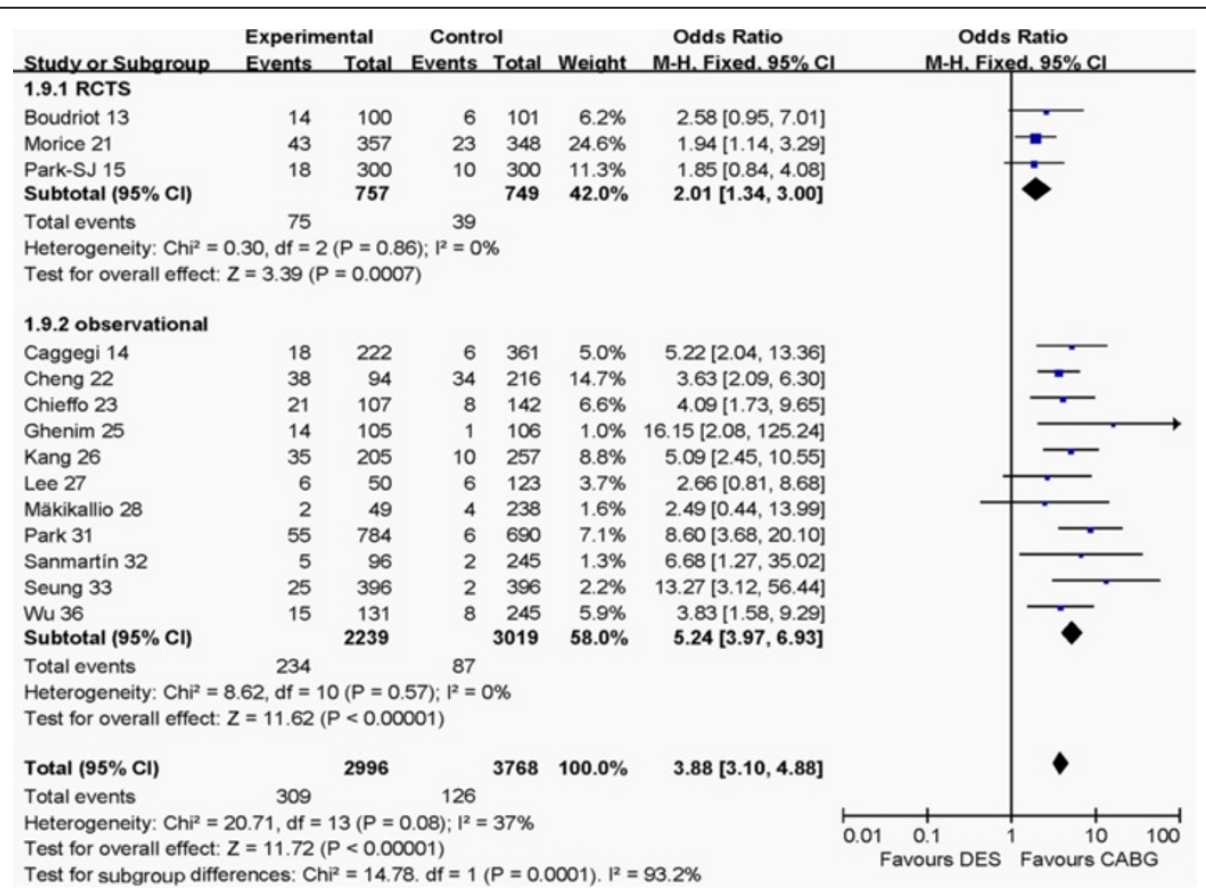

Figure 9 Comparison of DES and CABG for the outcome of revascularization at 1 year post-operation between RCT and observational groups. 


\begin{tabular}{|c|c|c|c|c|c|c|}
\hline \multicolumn{7}{|c|}{ Drug-Eluting Stents compared to Coronary Artery Bypass Grafting for left main coronary artery disease } \\
\hline \multicolumn{7}{|c|}{$\begin{array}{l}\text { Patient or population: patients with left main coronary artery disease } \\
\text { Intervention: Drug-Eluting Stents } \\
\text { Comparison: Coronary Artery Bypass Grafting }\end{array}$} \\
\hline \multirow[t]{3}{*}{ Outcomes } & \multicolumn{2}{|c|}{ IIlustrative comparative risks* $(95 \% \mathrm{Cl})$} & \multirow{3}{*}{$\begin{array}{l}\text { Relative effect } \\
(95 \% \mathrm{Cl})\end{array}$} & \multirow{3}{*}{$\begin{array}{l}\text { No of } \\
\text { Participants } \\
\text { (studies) }\end{array}$} & \multirow{3}{*}{$\begin{array}{l}\text { Quality of the } \\
\text { evidence } \\
\text { (GRADE) }\end{array}$} & \multirow[t]{3}{*}{ Comments } \\
\hline & Assumed risk & Corresponding risk & & & & \\
\hline & $\begin{array}{l}\text { Coronary Arte } \\
\text { Bypass Grafti }\end{array}$ & $\begin{array}{l}\text { Drug-Eluting } \\
\text { Stents }\end{array}$ & & & & \\
\hline \multirow{4}{*}{$\begin{array}{l}\text { the early } \\
\text { outcomes }(<30 \\
\text { days or In- } \\
\text { hospital early ). }\end{array}$} & \multicolumn{2}{|c|}{ Study population } & \multirow{4}{*}{$\begin{array}{l}\text { OR } 0.54 \\
(0.44 \text { to } 0.66)\end{array}$} & \multirow{4}{*}{$\begin{array}{l}11522 \\
\text { (14 studies) }\end{array}$} & \multirow{4}{*}{$\begin{array}{l}\oplus \oplus \oplus \odot \\
\text { moderate }{ }^{1,2,3}\end{array}$} & \\
\hline & 56 per 1000 & $\begin{array}{l}31 \text { per } 1000 \\
(25 \text { to } 38)\end{array}$ & & & & \\
\hline & \multicolumn{2}{|c|}{ Medium risk population } & & & & \\
\hline & 31 per 1000 & $\begin{array}{l}17 \text { per } 1000 \\
(14 \text { to } 21)\end{array}$ & & & & \\
\hline \multirow{4}{*}{$\begin{array}{l}\text { Comparison of } \\
\text { DES versus } \\
\text { CABG for the } \\
\text { outcome of } \\
\text { death from } 1 \\
\text { year to } 5 \text { years. }\end{array}$} & \multicolumn{2}{|c|}{ Study population } & \multirow{4}{*}{$\begin{array}{l}\text { RR } 0.78 \\
(0.7 \text { to } 0.86)\end{array}$} & \multirow{4}{*}{$\begin{array}{l}17901 \\
\text { (17 studies) }\end{array}$} & \multirow{4}{*}{$\begin{array}{l}\oplus \oplus \oplus 0 \\
\operatorname{low}^{\beta, 4}\end{array}$} & \\
\hline & 89 per 1000 & $\begin{array}{l}69 \text { per } 1000 \\
(62 \text { to } 77)\end{array}$ & & & & \\
\hline & \multicolumn{2}{|c|}{ Medium risk population } & & & & \\
\hline & 85 per 1000 & $\begin{array}{l}66 \text { per } 1000 \\
\text { (59 to } 73)\end{array}$ & & & & \\
\hline \multirow{4}{*}{$\begin{array}{l}\text { Comparison of } \\
\text { DES versus } \\
\text { CABG for the } \\
\text { outcome of } \\
\text { composite } \\
\text { endpoint of } \\
\text { death, MI, } \\
\text { cerebrovascular } \\
\text { events from } 1 \\
\text { year to } 5 \text { years. }\end{array}$} & \multicolumn{2}{|c|}{ Study population } & \multirow{4}{*}{$\begin{array}{l}\text { RR } 0.78 \\
(0.72 \text { to } 0.85)\end{array}$} & \multirow{4}{*}{$\begin{array}{l}17567 \\
\text { (16 studies) }\end{array}$} & \multirow{4}{*}{$\begin{array}{l}\oplus \oplus \oplus \bullet \\
\text { low } w^{3,4}\end{array}$} & \\
\hline & 123 per 1000 & $\begin{array}{l}96 \text { per } 1000 \\
(89 \text { to } 105)\end{array}$ & & & & \\
\hline & \multicolumn{2}{|c|}{ Medium risk population } & & & & \\
\hline & 127 per 1000 & $\begin{array}{l}99 \text { per } 1000 \\
(91 \text { to } 108)\end{array}$ & & & & \\
\hline \multirow{4}{*}{$\begin{array}{l}\text { Comparison of } \\
\text { DES versus } \\
\text { CABG for the } \\
\text { outcome of } \\
\text { revascularizatio } \\
n \text { from } 1 \text { year to } \\
5 \text { years. }\end{array}$} & \multicolumn{2}{|c|}{ Study population } & \multirow{4}{*}{$\begin{array}{l}\text { RR } 3.79 \\
\text { (3.37 to } 4.26 \text { ) }\end{array}$} & \multirow{4}{*}{$\begin{array}{l}18817 \\
\text { (21 studies) }\end{array}$} & \multirow{4}{*}{$\begin{array}{l}\oplus \oplus \oplus \odot \\
\text { moderate } 2,3,4\end{array}$} & \\
\hline & 36 per 1000 & $\begin{array}{l}136 \text { per } 1000 \\
(121 \text { to } 153)\end{array}$ & & & & \\
\hline & \multicolumn{2}{|c|}{ Medium risk population } & & & & \\
\hline & 35 per 1000 & $\begin{array}{l}\text { 133 per } 1000 \\
\text { (118 to } 149)\end{array}$ & & & & \\
\hline \multirow{4}{*}{$\begin{array}{l}\text { Comparison of } \\
\text { DES versus } \\
\text { CABG for the } \\
\text { outcome of RCT }\end{array}$} & Study popula & & RR 0.7 & 4089 & $\oplus \oplus \oplus \ominus$ & \\
\hline & 50 per 1000 & $\begin{array}{l}35 \text { per } 1000 \\
(26 \text { to } 47)\end{array}$ & & tudies) & lerate $e^{5,6}$ & \\
\hline & Medium risk & & & & & \\
\hline & 46 per 1000 & $\begin{array}{l}32 \text { per } 1000 \\
(24 \text { to } 43)\end{array}$ & & & & \\
\hline
\end{tabular}

${ }^{*}$ The basis for the assumed risk (e.g. the median control group risk across studies) is provided in footnotes. The corresponding risk (and its $95 \%$ confidence interval) is based on the assumed risk in the comparison group and the relative effect of the intervention (and its $95 \% \mathrm{Cl}$ ).

Cl: Confidence interval; RR: Risk ratio; OR: Odds ratio;

\section{GRADE Working Group grades of evidence}

High quality: Further research is very unlikely to change our confidence in the estimate of effect.

Moderate quality: Further research is likely to have an important impact on our confidence in the estimate of effect and may change the estimate.

Low quality: Further research is very likely to have an important impact on our confidence in the estimate of effect and is likely to change the estimate.

Very low quality: We are very uncertain about the estimate.

\footnotetext{
1 Two studies showed statistical difference, but they did not change the results

1 Two studies she
2 large effect

${ }^{3}$ Most of the baseline clinical characteristics between the PCI and CABG groups were not significant differences

${ }^{4}$ Most of trials did not Randomized controlled trials

${ }^{5}$ All trials describe the method of randomization and allocation concealment

${ }^{6}$ The pooled analysis showed a wide confidence interval
}

Figure 10 Summary of finding for the main comparison. 
characteristics among treatment groups might have an unknown influence on the estimated effects that would increase inconsistent results, and some trials in these groups had inconsistent results and high heterogeneity; all this also caused downgrade of the quality of evidence. Furthermore, only the articles in English were included in this analysis and we were unable to search for grey articles, which might be a source of potential publication bias in this study. The low quality of GRADE did not allow a robust conclusion for some groups in this population.

However, some total or subtotal RRs had a large effect. All RCTs describe the method of randomization and allocation concealment. These subgroups of RCT had consistent results and low heterogeneity, but the size of the study population of RCT was a bit small and the pooled analysis showed a wide CI. Therefore, some of the evidence GRADE level was moderate (Figure 10).

Other limitations should also be discussed in our study. Firstly, only four RCT were in the included studies in our meta-analysis, and two RCTs had duplicate patients and most types of data of outcomes in the two studies were repeated. Therefore, in the future, more randomized studies to compare DES with CABG in patients with left main coronary artery disease are necessary. What is more, many studies' period of follow-up was short and only three observational studies [23,30,31] reported long-term follow-up (5 years). Therefore, more long-term results are necessary in the future.

\section{Conclusions}

Our meta-analysis indicates that DES has a lower safety risk than CABG but is inferior to CABG for repeated revascularization in patients with ULMCAD in the 5 years after intervention. There was no difference in death, myocardial infarction, cerebrovascular events or revascularization between RCT and observational groups.

\section{Abbreviations}

CABG: Coronary artery bypass grafting; Cl: Confidence interval; DES: Drugeluting stents; PCl: Percutaneous coronary intervention; RR: Risk ratio; ULMCAD: Unprotected left main coronary artery disease.

\section{Competing interests}

The authors declare that they have no competing interests.

\section{Authors' contributions}

QL conceived the study, participated in the design, collected the data, performed statistical analyses, and drafted the manuscript. ZZ helped to collect the data and perform statistical analyses. RXY conceived the study, participated in the design, and helped to draft the manuscript. All authors read and approved the final manuscript.

\section{Acknowledgments}

This study was supported by the Science Foundation of Guangxi Returned Oversea Scholars (No: 0991004).

\section{Author details}

'Department of Cardiology, Institute of Cardiovascular Diseases, the First Affiliated Hospital, Guangxi Medical University, 22 Shuangyong Road, Nanning 530021 Guangxi, People's Republic of China. ${ }^{2}$ Department of Cardiology, Shanghai First People's Hospital, Shanghai Jiao Tong University School of Medicine, 200080, Shanghai, People's Republic of China.

Received: 21 October 2012 Accepted: 18 April 2013

Published: 8 May 2013

\section{References}

1. Lenzen MJ, Boersma E, Bertrand ME, Maier W, Moris C, Piscione F, Sechtem U, Stahle E, Widimsky P, de Jaegere P, op Reimer WJ S, Mercado N, Wijns W: Management and outcome of patients with established coronary artery disease: the Euro Heart Survey on coronary revascularization. Eur Heart $J$ 2005, 26:1169-1179.

2. Varnauskas E: Twelve-year follow-up of survival in the randomized European Coronary Surgery Study. N Engl J Med 1988, 319:332-337.

3. Taylor HA, Deumite NJ, Chaitman BR, Davis KB, Killip T, Rogers WJ: Asymptomatic left main coronary artery disease in the Coronary Artery Surgery Study (CASS) registry. Circulation 1989, 79:1171-1179.

4. Caracciolo EA, Davis KB, Sopko G, Kaiser GC, Corley SD, Schaff H, Taylor HA Chaitman BR: Comparison of surgical and medical group survival in patients with left main equivalent coronary artery disease. Long-term CASS experience. Circulation 1995, 91:2335-2344.

5. Patel MR, Dehmer GJ, Hirshfeld JW, Smith PK, Spertus JA: ACCF/SCAI/STS/ AATS/AHA/ASNC 2009 Appropriateness Criteria for Coronary Revascularization: a report by the American College of Cardiology Foundation Appropriateness Criteria Task Force, Society for Cardiovascular Angiography and Interventions, Society of Thoracic Surgeons, American Association for Thoracic Surgery, American Heart Association, and the American Society of Nuclear Cardiology Endorsed by the American Society of Echocardiography, the Heart Failure Society of America, and the Society of Cardiovascular Computed Tomography. J Am Coll Cardiol 2009, 53:530-553.

6. Marzocchi A, Saia F, Piovaccari G, Manari A, Aurier E, Benassi A, Cremonesi A, Percoco G, Varani E, Magnavacchi P, Guastaroba P, Grilli R, Maresta A: Long-term safety and efficacy of drug-eluting stents: two-year results of the REAL (REgistro AngiopLastiche dell'Emilia Romagna) multicenter registry. Circulation 2007, 115:3181-3188.

7. Lagerqvist B, James SK, Stenestrand U, Lindback J, Nilsson T, Wallentin L: Long-term outcomes with drug-eluting stents versus bare-metal stents in Sweden. N Engl I Med 2007, 356:1009-1019.

8. Smith SC Jr, Feldman TE, Hirshfeld JW Jr, Jacobs AK, Kern MJ, King SB 3rd, Morrison DA, O'Neil WW, Schaff HV, Whitlow PL, Williams DO, Antman EM, Adams CD, Anderson JL, Faxon DP, Fuster V, Halperin JL, Hiratzka LF, Hunt SA, Nishimura R, Ornato JP, Page RL, Riegel B, American College of Cardiology/ American Heart Association Task Force on Practice Guidelines; ACC/AHAVSCAI Writing Committee to Update 2001 Guidelines for Percutaneous Coronary Intervention: ACC/AHA/SCAI 2005 guideline update for percutaneous coronary intervention: a report of the American College of Cardiology/ American Heart Association Task Force on Practice Guidelines (ACC/AHA/ SCAI Writing Committee to Update 2001 Guidelines for Percutaneous Coronary Intervention). Circulation 2006, 113:166-286.

9. Kajimoto K, Miyauchi K, Yamamoto T, Daida H, Amano A: Meta-analysis of randomized controlled trials on the treatment of unprotected left main coronary artery disease: one-year outcomes with coronary artery bypass grafting versus percutaneous coronary artery intervention with drug-eluting stent. J Card Surg 2012, 27:152-157.

10. Lee MS, Yang T, Dhoot J, Liao H: Meta-analysis of clinical studies comparing coronary artery bypass grafting with percutaneous coronary intervention and drug-eluting stents in patients with unprotected left main coronary artery narrowings. Am J Cardiol 2010, 105:1070-1075.

11. Takagi $\mathrm{H}$, Umemoto T: A meta-analysis of randomized trials and adjusted observational studies of drug-eluting stents versus coronary artery bypass grafting for unprotected left main coronary artery disease. Int J Cardiol 2011, 150:341-343.

12. Zheng S, Zheng Z, Hou J, Hu S: Comparison between drug-eluting stents and coronary artery bypass grafting for unprotected left main coronary artery disease: a meta-analysis of two randomized trials and thirteen observational studies. Cardiology 2011, 118:22-32. 
13. Boudriot $E$, Thiele $H$, Walther $T$, Liebetrau $C$, Boeckstegers $P$, Pohl $T$, Reichart $B$, Mudra H, Beier F, Gansera B, Neumann FJ, Gick M, Zietak T, Desch S, Schuler G, Mohr FW: Randomized comparison of percutaneous coronary intervention with sirolimus-eluting stents versus coronary artery bypass grafting in unprotected left main stem stenosis. J Am Coll Cardio/ 2011, 57:538-545.

14. Caggegi A, Capodanno D, Capranzano P, Chisari A, Ministeri M, Mangiameli A Ronsivalle G, Ricca G, Barrano G, Monaco S, Di Salvo ME, Tamburino C: Comparison of one-year outcomes of percutaneous coronary intervention versus coronary artery bypass grafting in patients with unprotected left main coronary artery disease and acute coronary syndromes (from the CUSTOMIZE Registry). Am J Cardiol 2011, 108:355-359.

15. Park SJ, Kim YH, Park DW, Yun SC, Ahn JM, Song HG, Lee JY, Kim WJ, Kang SJ, Lee SW, Lee CW, Park SW, Chung CH, Lee JW, Lim DS, Rha SW, Lee SG,

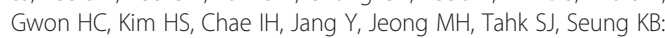
Randomized trial of stents versus bypass surgery for left main coronary artery disease. N Engl J Med 2011, 364:1718-1727.

16. Rittger H, Rieber J, Kogler K, Sinha A, Schmidt M, Breithardt OA, Biggar P, Einsle F, Diegeler A, Brachmann J: Clinical outcome and quality of life after interventional treatment of left main disease with drug-eluting-stents in comparison to CABG in elderly and younger patients. Clin Res Cardiol 2011, 100:439-446.

17. Higgins JPT, Green S: Cochrane handbook for systematic reviews of interventions version 5.1.0 [updated March 2011]. The Cochrane Collaboration 2011. Available at: www.cochrane-handbook.org.

18. Higgins JP, Thompson SG, Deeks JJ, Altman DG: Measuring inconsistency in meta-analyses. BMJ 2003, 327:557-560.

19. Higgins JPT, Green S: Cochrane handbook for systematic reviews of interventions version 5.0.0 [updated February 2008]. The Cochrane Collaboration 2008. Available at: www.cochrane-handbook.org.

20. Boudriot E, Liebetrau C, Walther T, Thiele H, Pohl T, Boeckstegers P, Reichart B, Beier F, Mudra H, Kemkes BM, Gick M, Neumann FJ, Schuler G, Mohr FW: Randomized, multicenter trial between $\mathrm{PCl}$ with sirolimus eluting stent and CABG for patients with unprotected left main stenosis. 1-year -results. Circulation 2008, 118:739.

21. Morice MC, Serruys PW, Kappetein AP, Feldman TE, Stahle E, Colombo A, Mack MJ, Holmes DR, Torracca L, van Es GA, Leadley K, Dawkins KD, Mohr F: Outcomes in patients with de novo left main disease treated with either percutaneous coronary intervention using paclitaxel-eluting stents or coronary artery bypass graft treatment in the Synergy Between Percutaneous Coronary Intervention with TAXUS and Cardiac Surgery (SYNTAX) trial. Circulation 2010, 121:2645-2653.

22. Cheng Cl, Lee FY, Chang JP, Hsueh SK, Hsieh YK, Fang CY, Chen SM, Yang $\mathrm{CH}$, Yip HK, Chen MC, Fu M, Wu CJ: Long-term outcomes of intervention for unprotected left main coronary artery stenosis: coronary stenting vs coronary artery bypass grafting. Circ J 2009, 73:705-712.

23. Chieffo A, Magni V, Latib A, Maisano F, lelasi A, Montorfano M, Carlino M, Godino C, Ferraro M, Calori G, Alfieri O, Colombo A: 5-year outcomes following percutaneous coronary intervention with drug-eluting stent implantation versus coronary artery bypass graft for unprotected left main coronary artery lesions the Milan experience. JACC Cardiovasc Interv 2010, 3:595-601.

24. Chieffo A, Morici N, Maisano F, Bonizzoni E, Cosgrave J, Montorfano M, Airoldi F, Carlino M, Michev I, Melzi G, Sangiorgi G, Alfieri O, Colombo A Percutaneous treatment with drug-eluting stent implantation versus bypass surgery for unprotected left main stenosis: a single-center experience. Circulation 2006, 113:2542-2547.

25. Ghenim R, Roncalli J, Tidjane AM, Bongard V, Ziani A, Boudou N, Dumonteil N, Marcheix B, Leobon B, Carrie D: One-year follow-up of nonrandomized comparison between coronary artery bypass grafting surgery and drug-eluting stent for the treatment of unprotected left main coronary artery disease in elderly patients (aged > or $=75$ years). J Interv Cardio/ 2009, 22:520-526.

26. Kang SH, Park KH, Choi DJ, Park KW, Chung WY, Lim C, Kim KB, Kim HS: Coronary artery bypass grafting versus drug-eluting stent implantation for left main coronary artery disease (from a two-center registry). Am J Cardiol 2010, 105:343-351.

27. Lee MS, Kapoor N, Jamal F, Czer L, Aragon J, Forrester J, Kar S, Dohad S, Kass R, Eigler N, Trento A, Shah PK, Makkar RR: Comparison of coronary artery bypass surgery with percutaneous coronary intervention with drug-eluting stents for unprotected left main coronary artery disease. J Am Coll Cardiol 2006, 47:864-870.
28. Makikallio TH, Niemela M, Kervinen K, Jokinen V, Laukkanen J, Ylitalo I, Tulppo MP, Juvonen J, Huikuri HV: Coronary angioplasty in drug eluting stent era for the treatment of unprotected left main stenosis compared to coronary artery bypass grafting. Ann Med 2008, 40:437-443.

29. Palmerini T, Barlocco F, Santarelli A, Bacchi-Reggiani L, Savini C, Baldini E, Alessi L, Ruffini M, Di Credico G, Piovaccari G, Di Bartolomeo R, Marzocchi A Branzi A, De Servi S: A comparison between coronary artery bypass grafting surgery and drug eluting stent for the treatment of unprotected left main coronary artery disease in elderly patients (aged $>$ or $=75$ years). Eur Heart J 2007, 28:2714-2719.

30. Park DW, Kim YH, Yun SC, Lee JY, Kim WJ, Kang SJ, Lee SW, Lee CW, Kim JJ, Choo SJ, Chung CH, Lee JW, Park SW, Park SJ: Long-term outcomes after stenting versus coronary artery bypass grafting for unprotected left main coronary artery disease: 10-year results of bare-metal stents and 5-year results of drug-eluting stents from the ASAN-MAIN (ASAN Medical CenterLeft MAIN Revascularization) Registry. J Am Coll Cardiol 2010, 56:1366-1375.

31. Park DW, Seung KB, Kim YH, Lee JY, Kim WJ, Kang SJ, Lee SW, Lee CW, Park SW, Yun SC, Gwon HC, Jeong MH, Jang YS, Kim HS, Kim PJ, Seong IW, Park HS, Ahn T, Chae IH, Tahk SJ, Chung WS, Park SJ: Long-term safety and efficacy of stenting versus coronary artery bypass grafting for unprotected left main coronary artery disease: 5-year results from the MAIN-COMPARE (Revascularization for Unprotected Left Main Coronary Artery Stenosis: Comparison of Percutaneous Coronary Angioplasty Versus Surgical Revascularization) registry. J Am Coll Cardiol 2010, 56:117-124.

32. Sanmartin M, Baz JA, Claro R, Asorey V, Duran D, Pradas G, Iniguez A Comparison of drug-eluting stents versus surgery for unprotected left main coronary artery disease. Am J Cardio/ 2007, 100:970-973.

33. Seung KB, Park DW, Kim YH, Lee SW, Lee CW, Hong MK, Park SW, Yun SC, Gwon HC, Jeong MH, Jang Y, Kim HS, Kim PJ, Seong IW, Park HS, Ahn T, Chae $\|$, Tahk SJ, Chung WS, Park SJ: Stents versus coronary-artery bypass grafting for left main coronary artery disease. N Engl J Med 2008, 358:1781-1792.

34. Shimizu T, Ohno T, Ando J, Fujita H, Nagai R, Motomura N, Ono M, Kyo S, Takamoto S: Mid-term results and costs of coronary artery bypass vs. drug-eluting stents for unprotected left main coronary artery disease. Circ J 2010, 74:449-455.

35. White AJ, Kedia G, Mirocha JM, Lee MS, Forrester JS, Morales WC, Dohad S, Kar S, Czer LS, Fontana GP, Trento A, Shah PK, Makkar RR: Comparison of coronary artery bypass surgery and percutaneous drug-eluting stent implantation for treatment of left main coronary artery stenosis. JACC Cardiovasc Interv 2008, 1:236-245.

36. Wu X, Chen Y, Liu H, Teirstein PS, Kirtane AJ, Ge C, Song X, Chen X, Gu C, Huang F, LV S: Comparison of long-term (4-year) outcomes of patients with unprotected left main coronary artery narrowing treated with drug-eluting stents versus coronary-artery bypass grafting. Am J Cardiol 2010, 105:1728-1734.

37. Naik H, White AJ, Chakravarty T, Forrester J, Fontana G, Kar S, Shah PK, Weiss RE, Makkar R: A meta-analysis of 3,773 patients treated with percutaneous coronary intervention or surgery for unprotected left main coronary artery stenosis. JACC Cardiovasc Interv 2009, 2:739-747.

38. Serruys PW, Morice MC, Kappetein AP, Colombo A, Holmes DR, Mack MJ, Stahle E, Feldman TE, van den Brand M, Bass EJ, Van Dyck N, Leadley K, Dawkins KD, Mohr FW: Percutaneous coronary intervention versus coronary-artery bypass grafting for severe coronary artery disease. N Engl J Med 2009, 360:961-972.

39. Cohen DJ, Van Hout B, Serruys PW, Mohr FW, Macaya C, den Heijer P, Vrakking MM, Wang K, Mahoney EM, Audi S, Leadley K, Dawkins KD, Kappetein AP: Quality of life after PCl with drug-eluting stents or coronary-artery bypass surgery. N Engl J Med 2011, 364:1016-1026.

40. Desch S, Boudriot E, Rastan A, Buszman PE, Bochenek A, Mohr FW, Schuler $G$, Thiele $H$ : Bypass surgery versus percutaneous coronary intervention for the treatment of unprotected left main disease: a meta-analysis of randomized controlled trials. Herz 2013, 38:48-56.

41. Buszman PE, Kiesz SR, Bochenek A, Peszek-Przybyla E, Szkrobka I, Debinski M, Bialkowska B, Dudek D, Gruszka A, Zurakowski A, Milewski K, Wilczynski M, Rzeszutko L, Buszman P, Szymszal J, Martin JL, Tendera M: Acute and late outcomes of unprotected left main stenting in comparison with surgical revascularization. J Am Coll Cardiol 2008, 51:538-545.

doi:10.1186/1745-6215-14-133

Cite this article as: Li et al.: Drug-eluting stents or coronary artery bypass grafting for unprotected left main coronary artery disease: a meta-analysis of four randomized trials and seventeen observational studies. Trials 2013 14:133. 